\title{
The Impact of COVID-19 on Hospital Attendance and Perceived Stigmatization Towards Individuals with COVID-19 Like Symptoms in Buea Municipality, Cameroon
}

\author{
Tendongfor Nicholas ${ }^{1, ~}$, Njingti Ruth Bongngi ${ }^{2}$, Mapoure Njankouo Yacouba ${ }^{3}$, \\ Ebiambu Ondoh Agwara ${ }^{2}$, Ako Carol Shenelle Mbeng ${ }^{1}$ \\ ${ }^{1}$ Department of Public Health and Hygiene, University of Buea, Buea, Cameroon \\ ${ }^{2}$ Department of Medicine, Faculty of Health Sciences, University of Buea, Buea, Cameroon \\ ${ }^{3}$ Faculty of Medicine and Pharmaceutical Sciences, University of Douala, Douala, Cameroon
}

\section{Email address:}

ntendongfor@gmail.com (T. Nicholas), njingtiruth4@gmail.com (N. R. Bongngi), mapoureyacouba@gmail.com (M. N. Yacouba), ebiambuagwara@gmail.com (E. O. Agwara)

${ }^{*}$ Corresponding author

\section{To cite this article:}

Tendongfor Nicholas, Njingti Ruth Bongngi, Mapoure Njankouo Yacouba, Ebiambu Ondoh Agwara, Ako Carol Shenelle Mbeng. The Impact of COVID-19 on Hospital Attendance and Perceived Stigmatization Towards Individuals with COVID-19 Like Symptoms in Buea Municipality, Cameroon. International Journal of Clinical and Experimental Medical Sciences. Vol. 7, No. 2, 2021, pp. 37-43. doi: $10.11648 /$ j.ijcems.20210702.11

Received: February 9, 2021; Accepted: February 24, 2021; Published: March 4, 2021

\begin{abstract}
Objectives: The outbreak of COVID-19 has brought about fear and uncertainty resulting to stigmatization and discrimination towards those with COVID-19 like symptoms as well as influence the patient influx to health facilities and the health-seeking behaviour of the population. This study assessed the health-seeking behaviour, hospital attendance, and the level of stigmatization of the population towards individuals with COVID-19 like symptoms. Methods: This was a cross-sectional community and hospital-based study carried out to assess hospital attendance, perceived stigmatization and population health-seeking behaviour during the COVID-19 pandemic in the Buea Municipality. The trend in the patients' influx in the COVID-19 treatment centre and other health facilities was assessed from March to June 2020 and compared with corresponding months in 2019. The stigmatization data was collected using a modified 12-items stigma scale. The data was analyzed with SPSS version 26. Results: The hospital attendance decreased in the COVID-19 treatment centre from April to June 2020 by $-38.3 \%$ and increased in non-COVID-19 treatment health facilities by over $70 \%$. Of the 570 participants for the community survey, 322 (56.5\%) reported to go for auto medication if they developed COVID-19 symptoms. Individuals with COVID-19 like symptoms experienced moderate (59.1\%) to severe (33.9\%) perceived stigmatization. Perceived stigmatization was significantly higher $\left(\chi^{2}=14.56, p=0.001\right)$ in participants who reported not willing to go to the hospital during the pandemic. Conclusion: The hospital turnout experienced a drop in the COVID-19 treatment centre and an increase in other health facilities. There was high perceived stigmatization towards people with COVID-19 like symptoms, which probably accounted for the population refusal to seek treatment in the COVID-19 treatment center and to resort to auto medication.
\end{abstract}

Keywords: Perceived Stigmatization, Health-seeking Behaviour, Hospital Attendance, Auto-medication, COVID-19

\section{Background}

In late December 2019, several local health facilities in Wuhan, China reported clusters of patients with pneumonia. The novel coronavirus $(2019-\mathrm{nCoV})$ or the severe acute respiratory syndrome coronavirus 2 (SARS-CoV-2) causative agent of this pneumonia has claimed many lives since the beginning of the outbreak $[1,2]$. It was later declared a pandemic on the $11^{\text {th }}$ of March 2020 [3]. The emergence of the COVID-19 pandemic did not only bring forth negative health consequences, but also social consequences like misinformation, over information, stigmatization, 
discrimination, and herd behavior [4].

This has had a negative impact on the patient influx to the hospitals and brought a lot of stigma and discrimination at the community level, as well as a negative impact on the population health-seeking behaviour [5, 6]. Many of the recovered patients have been denied reintegration in their communities with the perception that they may be reinfected and transmit the virus to others [7]. This attitude and stigma shown by the community has hampered the control of the infection at the community level and created more difficulties in tracing contact of COVID-19 infected people. In addition, to avoid discrimination due to the stigma attached to the disease, people may be driven towards behaviors including hiding their illness and not seeking healthcare.

A drop in patient influx to hospitals has been reported since the onset of the pandemic [8-11]. Patients would rather stay at home or depend on auto-medications, roadside vendors, or use home-made concoctions if they suspect COVID-19 infection [12]. The misconceptions surrounding the disease and fear of getting infected has also led to the stigmatization of patients with related symptoms [5]. This study aimed at documenting the hospital attendance and population health-seeking behaviour during the pandemic as well as assessing the level of perceived stigmatization of the population towards individuals with COVID-19 like symptoms in Buea Municipality, Cameroon.

\section{Methods}

\subsection{Study Site}

The study was carried out in Buea, the administrative headquarter of the South West Region of Cameroon, one of the Regions affected by the Anglophone crisis since 2016. Buea is a town located on the eastern slopes of Mount Cameroon and lies between latitudes $4^{\circ} 12^{\prime} \mathrm{N}$ and longitudes $9^{\circ} 12^{\prime} \mathrm{E}$ with a total surface area of $870 \mathrm{~km}^{2}$. The total population estimated by the health population denominators in 2013 revealed 300,000 inhabitants [13]. The population mainly consists of students and civil servants who are highly concentrated in Molyko. Many internally displaced people from neighbouring villages affected by the Anglophone crisis since 2016 have found refuge in Buea municipality. The epidemiological data were collected in four health areas (Buea Road, Molyko, Muea and Bokwango) out of the eight health areas in the Buea Health District while the hospital attendance was collected from 9 health facilities namely; the Regional Hospital Buea (COVID-19 treatment centre), Solidarity Clinic, Saint Veronica Teaching Hospital, $7^{\text {th }}$ Day Adventist Clinic, Buea Road Health Center, Bokwoango Integrated Health Center, Buea Town Health Center, Molyko Integrated Health Center And Muea Medicalized Health Center.

\subsection{Study Design and Target Population}

The study was a cross-sectional study in which data on the perceived stigmatization of population towards individuals with COVID-19 like symptoms were collected in selected communities using a questionnaire and hospital attendance recorded for the months of March to June 2020 and 2019 respectively in selected health facilities. The study population consisted of males and females, age 18 years and above residing in the Buea Municipality.

\subsection{Data Collection Tools}

This study was conducted using 2 tools; a selfadministered multiple-choice questionnaire for the community survey and a data collection form for the hospital attendance data.

The questionnaire consisted of 2 parts: the first part ( 6 questions) assessed the population's attitudes towards hospital attendance and health-seeking habit during the pandemic. This part dealt with finding out whether the population will seek healthcare from health facilities and whether they thought it was ok going to hospitals during the pandemic. The second part evaluated the levels of perceived stigmatization of the population towards individuals with COVID-19 liked symptoms. A modified stigmatization scale adapted from a study carried out in Italy by Ramaci et al. was used [4]. The scale comprised of 12-items which were scored on a 5-points Likert scale. The questions evaluated perceived stigmatization in the population. The 5points Likert scale was scored as follows: strongly disagree $=3$, disagree $=2$, agree $=1$ and strongly agree $=0$. Negative questions were reverse-scored to ensure the direction was consistent for the answers. Scores ranging from 1 to 8 were graded Mild perceived stigma, 9 to 15 Moderate perceived stigma, and $>16$ Severe perceived stigma.

\subsection{Sampling}

For the hospital attendance study, the health facilities were purposively selected and included four hospitals, two medicalized health centers and three Integrated Health centres. The out-patient registers were accessed and the number of patients who consulted in the health facilities was recorded for the months of March to June 2020 and 2019 respectively.

For the community based cross-sectional study, a twostage random sampling was used to select four health areas from which 2 to five communities were selected for the study. The data on perceived stigmatization of the population towards individuals with COVID-19 like symptoms in the community was collected with a closed-ended questionnaire adapted from a study carried out in Italy [4]. We included in the study males and females aged 18 years and above recruited in selected communities and who consented by signing the consent form. Data was collected from households and hot spots (meeting points, motor parks, restaurants, and workshops). In each household visited at most two persons were interviewed. Individuals interviewed were of different age groups and gender. The questionnaire was administered to participants in the English language. 
Literate participants were allowed to fill the questionnaire themselves whereas for those who could not read or write, the questionnaire was administered in Pidgin (broken English) a language well understood in the area. A minimum sample size of 384 was determined using the Lorenz formula with an expected proportion of the population having accurate knowledge of the virus adapted from our previous study carried out in Buea [13].

\subsection{Data Management and Analysis}

The data collected was entered into a template created in MS Excel and analyzed with the Statistical Package for the Social Sciences (SPSS) version 26. The data were summarized using descriptive statistics and the results displayed in charts and tables. A $p$-value $<0.05$ was considered statistically significant. The associations between level of perceived stigmatization and health seeking behaviour and sociodemographic characteristics was determined using the chi-square test.

\subsection{Ethical Considerations}

All procedures performed in this study were in accordance with the ethical standards of the Institutional Review Board
(IRB) of the Faculty of Health Sciences, University of Buea (Reference Number 2020/1096-01/UB/SG/IRB/FHS) and with the 1964 Helsinki declaration and its later amendments or comparable ethical standards. Administrative authorization to carry out the research was obtained from the Regional Delegation of Public Health for the South West Region (Reference number: R11/MINSANTE/SWR/RDPH/PS/800/882) and the district health service of Buea (Reference number F1V012/L/MINSANTE/RDPHSW/DHS/BUEA/178).

\section{Results}

\subsection{Sociodemographic Characteristics of the Study Population}

A total of 600 questionnaires were filled of which 30 questionnaires were rejected for incomplete data. The ages of the participants ranged from 18 to 65 years with a mean age of $28.08 \pm 9.61$ years, $336(58.9 \%)$ were between $20-29$ years, $332(56.5 \%)$ were females, $176(30.9 \%)$ were recruited in Molyko, 371 (65.1\%) were singles and 544 (95.4\%) were Christians (Table 1).

Table 1. Sociodemographic data of the study population.

\begin{tabular}{|c|c|c|c|}
\hline Variable & Level & Frequency & Percentage \\
\hline \multirow{5}{*}{ Age group } & $<20$ years & 53 & 9.3 \\
\hline & $20-29$ years & 336 & 58.9 \\
\hline & $30-39$ years & 108 & 18.9 \\
\hline & 40 - 49 years & 39 & 6.8 \\
\hline & $50+$ & 34 & 6.0 \\
\hline \multirow{5}{*}{ Quarter } & Bomaka & 146 & 25.6 \\
\hline & Bonduma & 95 & 16.7 \\
\hline & Molyko & 176 & 30.9 \\
\hline & Muea & 59 & 10.4 \\
\hline & Soppo & 72 & 12.6 \\
\hline Gender & Female & 322 & 56.5 \\
\hline \multirow{4}{*}{ Marital Status } & Divorce & 6 & 1.1 \\
\hline & Married & 186 & 32.6 \\
\hline & Single & 371 & 65.1 \\
\hline & Widowed & 7 & 1.2 \\
\hline \multirow{3}{*}{ Religion } & Christian & 544 & 95.4 \\
\hline & Muslim & 21 & 3.7 \\
\hline & Others & 5 & 0.9 \\
\hline
\end{tabular}

\subsection{Hospital Attendance During the COVID-19 Pandemic in the Buea Municipality}

Overall, the patient turnout at the level of the hospitals increased for March 2019 (2702) to March 2020 (3750) representing a $+38.8 \%$ change. A positive increase of $+0.30 \%$ was also observed between April 2019 and April 2020. However, a decrease in patient turnout was observed from May to June 2020 when compared with their respective months in 2019 by $-7.4 \%$ and $-10.9 \%$ respectively.

At the COVID-19 treatment centre, there was a $+50.6 \%$ increase for March 2020 when compared with March 2019 A decrease of $-13.1 \%,-29.2 \%$ and $-38.3 \%$ was observed in April, May and June 2020 when compared with their respective months for 2019 . It was observed that the 
patient turn out in the COVID-19 treatment centre dropped from 2302 patients in March 2020 (month of onset of the pandemic in Cameroon) to 1209 patients in June 2020 (three months into the pandemic) representing a $-38.3 \%$.

In the Health centers, the percentage change for patient turnout at the level of the MHC was $-13.3 \%$ for March 2020, $+42.3 \%$ for April $2020,+35.4 \%$ for May 2020 , and $+74.8 \%$ for June when compared with their respective months in 2019. The Integrated Health Centres, percentage change was $+44.3 \%$ for March 2020, $+16.3 \%$ for April $2020,+64.9 \%$ for May, and $+157.1 \%$ for June when compared with their respective months in 2019. There was an overall increase in patient turnout for both the Medicalized Health Centres and Integrated Health Centres (Table 2).

Table 2. Percentage change of patient turnout at the health facilities for the months of March-June in for the years 2019 and 2020.

\begin{tabular}{lllll}
\hline Months & MHC & IHC & Hospitals & COVID-19 centre \\
\hline March & $15.2 \%$ & $44.3 \%$ & $38.80 \%$ & $50.6 \%$ \\
April & $52.3 \%$ & $16.9 \%$ & $0.30 \%$ & $-13.1 \%$ \\
May & $-6.7 \%$ & $64.9 \%$ & $-7.40 \%$ & $-29.2 \%$ \\
June & $74.8 \%$ & $157.1 \%$ & $-10.90 \%$ & $-38.3 \%$ \\
\hline
\end{tabular}

\subsection{Population Health-Seeking Behaviour During the COVID-19 Pandemic}

Of the 570 participants interviewed, $56.5 \%$ reported they will go for auto-medication if they developed Covid-19 symptoms, $31.3 \%$ will seek care from the hospitals, $8.1 \%$ will go for traditional medicine and $7.0 \%$ reported they would invite a doctor or nurse to their homes (Figure 1). Reasons advanced by participants justifying unorthodox health practices were fear of being infected by the COVID-19 virus in the hospitals (22\%) and fear of being quarantined (27.2\%).

\subsection{Perceived Stigmatization Towards Individuals with COVID-19 Like Symptoms}

The perceived stigmatization towards individuals with
COVID-19 like symptoms in the community was moderate in $337(59.1 \%)$, severe in $139(33.9 \%)$ and low in $40(7.0 \%)$ participants (Figure 2).

\subsection{Association Between the Levels of Stigmatization and the Population Willingness to Go to the Hospital}

There was a significant association between the level of perceived stigmatization and the population's willingness to go to the hospital. Those who were not willing to go to the hospital had significantly higher (Chi-square $\left.=14.56, \mathrm{p}_{=} 0.001\right)$ level of perceived stigmatization (Figure 3) compared to those who were willing to visit the hospital during the COVID-19 pandemic. There was no association between the level of perceived stigmatization and sociodemographic characteristics (Table 3).

Table 3. Levels of stigmatization and sociodemographic characteristics.

\begin{tabular}{|c|c|c|c|c|c|c|}
\hline \multirow{2}{*}{ Variables } & & \multicolumn{3}{|c|}{ Levels of stigma } & \multirow{2}{*}{ Chi-square } & \multirow{2}{*}{ p-value } \\
\hline & & Low & Moderate & Severe & & \\
\hline \multirow{4}{*}{ Health areas } & Bokwango & $0(0.0 \%)$ & $15(2.6 \%)$ & $7(1.2 \%)$ & \multirow{4}{*}{8.154} & \multirow{4}{*}{0.227} \\
\hline & Buea road & $12(2.1 \%)$ & $97(17.0 \%)$ & $58(10.2 \%)$ & & \\
\hline & Molyko & $19(3.3 \%)$ & $102(17.9 \%)$ & $55(9.6 \%)$ & & \\
\hline & Muea & $9(1.6 \%)$ & $123(21.6 \%)$ & $73(12.8 \%)$ & & \\
\hline \multirow{5}{*}{ Age group } & $<20$ years & $7(1.2 \%)$ & $27(4.7 \%)$ & $19(3.3 \%)$ & \multirow{5}{*}{13.07} & \multirow{5}{*}{0.109} \\
\hline & $20-29$ years & $20(3.5 \%)$ & $189(33.2 \%)$ & $127(22.3 \%)$ & & \\
\hline & 30 - 39 years & $7(1.2 \%)$ & $71(12.5 \%)$ & $30(5.3 \%)$ & & \\
\hline & 40 - 49 years & $2(0.4 \%)$ & $28(4.9 \%)$ & $9(1.6 \%)$ & & \\
\hline & $50+$ & $4(0.7 \%)$ & $22(3.9 \%)$ & $8(1.4 \%)$ & & \\
\hline \multirow{2}{*}{ Gender } & Female & $24(4.2 \%)$ & $178(31.2 \%)$ & $120(21.1 \%)$ & \multirow{2}{*}{4.59} & \multirow{2}{*}{0.101} \\
\hline & Male & $16(2.8 \%)$ & $159(27.9 \%)$ & $73(12.8 \%)$ & & \\
\hline \multirow{2}{*}{ Marital status } & Married & $17(3.0 \%)$ & $116(20.4 \%)$ & $53(9.3 \%)$ & \multirow{2}{*}{4.61} & \multirow{2}{*}{0.100} \\
\hline & Single & $23(4.0 \%)$ & $221(38.8 \%)$ & $140(24.6 \%)$ & & \\
\hline \multirow{3}{*}{ Religion } & Christian & $36(6.3 \%)$ & $320(56.1 \%)$ & $188(33.0 \%)$ & \multirow{3}{*}{8.64} & \multirow{3}{*}{0.071} \\
\hline & Muslim & $4(0.7 \%)$ & $12(2.1 \%)$ & $5(0.9 \%)$ & & \\
\hline & Others & $0(0.0 \%)$ & $5(0.9 \%)$ & $0(0.0 \%)$ & & \\
\hline
\end{tabular}




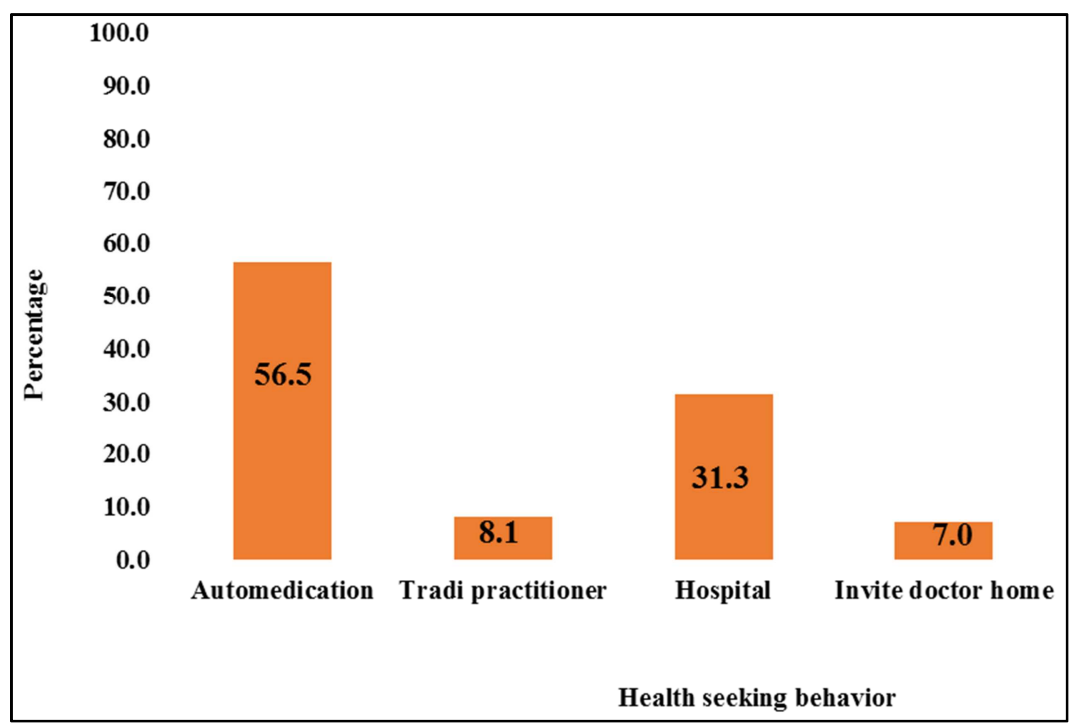

Figure 1. Health-seeking behaviour of the population in case of Covid-19 symptoms.

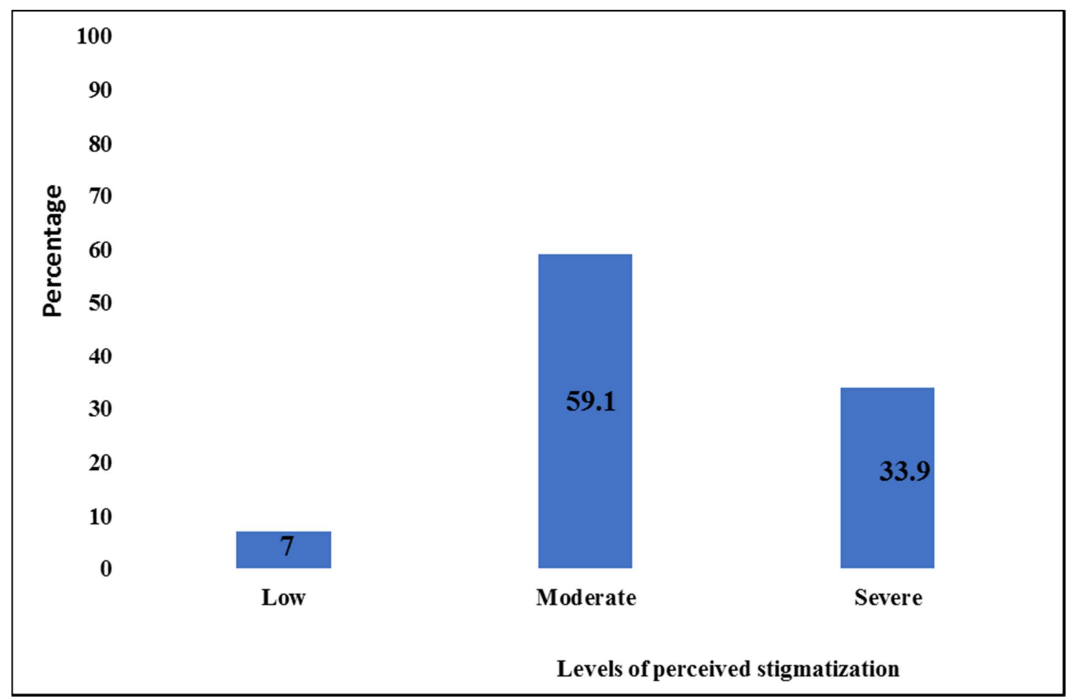

Figure 2. Levels of perceived stigmatization in the Buea population.

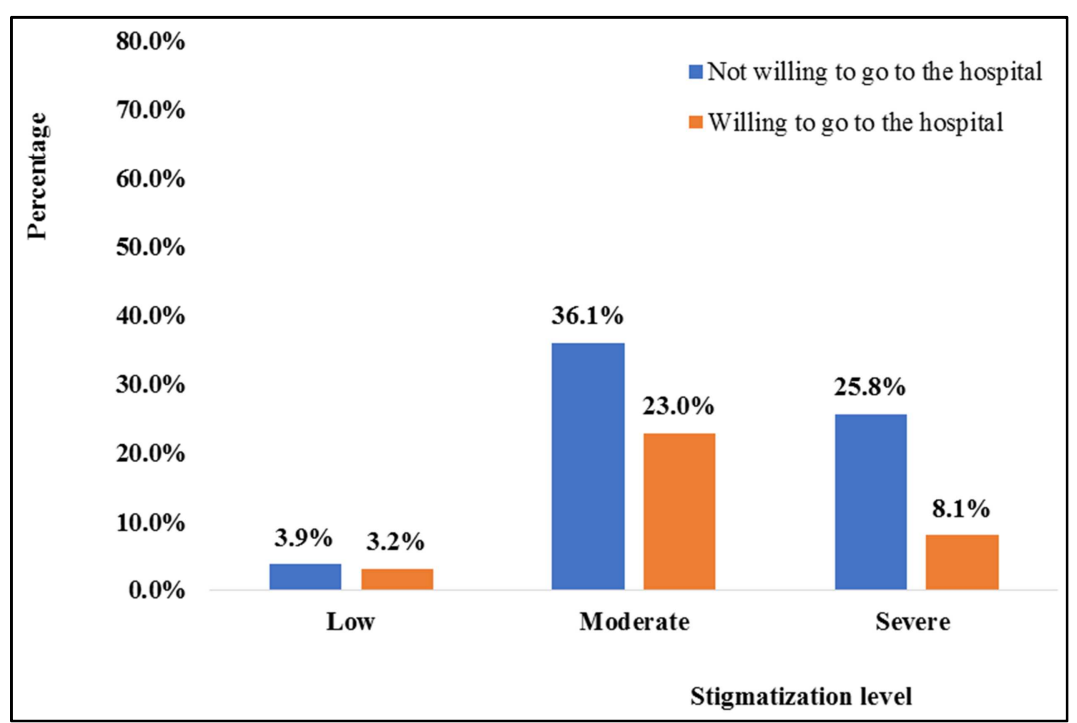

Figure 3. Association between level of perceived stigma and individual willingness to visit the hospital during the COVID-19 pandemics, (Chi-square=14.56, p. 0.001). 


\section{Discussion}

The outbreak of COVID-19 has brought about fear and uncertainty resulting in stigmatization, discrimination towards patients, and individuals with COVID-19 like symptoms as well as an alteration the in health-seeking behaviour of the population. It has also influenced the patient influx to health facilities and the health-seeking behaviour of the population. Measuring the impact of COVID-19 on the hospital attendance, health-seeking behaviour of, and perceived stigmatization of the population toward COVID-19 could help decision-makers put in place strategies to mitigate stigmatization among the population.

It was observed in this study that the hospital turnout was affected from the onset to three months into the pandemic. The effect was a lot felt in the lone COVID-19 treatment centre in Buea in contrast to the non-COVID-19 treatment hospitals, medicalized health centres and integrated health centres which experienced an increase in patient turnout for the same period. Because of the fear and stigma associated with COVID-19, there was a tendency for the population to avoid the lone COVID-19 treatment centre in Buea, therefore preferring visiting other health facilities or resorting to auto medication.

The first case of COVID-19 was reported in Cameroon in March 2020. By then the effect was not yet felt in Buea. This justifies the increase in hospital turnout for March 2020 when compared with March 2019. However, the low turnout in the COVID-19 treatment centre from April to June could be explained by the fact that the first cases of infection were reported in Buea in April 2020. This instilled fear in the population, causing them to seek health care from health facilities different from the Regional Hospital, the lone COVID-19 treatment centre. Similar findings were reported in a study conducted in Cleveland, USA which recorded a decrease in patient turnout for March 2020 to May 2020 when compared to their respective months in 2019 [8]. In another study conducted in California, USA a decrease in emergency consultations was also reported during the pandemic [9]. Our findings also confirm the results of studies conducted in the United Kingdom and Hongkong $[10,11]$.

A little above half of the participants reported their healthseeking behaviour to be towards auto-medication during the pandemic. The choice of auto-medication over hospital care as a health-seeking behaviour was explained by the fear of being quarantined and getting infected as reported by the participants. These findings were similar to those reported in a study conducted in Nepal [12], however, their results differed from ours because their participants chose herbal remedies as their health-seeking behaviour. In our study only a few participants reported they will go for herbal remedy.

The level of perceived stigma documented among the participants supports the link between stigma and the amount of threat that a new disease can generate [14]. The level of perceived stigma was homogeneously distributed over the population in Buea irrespective of the age, gender, health area, marital status, and religion of the inhabitants. The fact that the population was much stigmatized contributed significantly to their willingness not to go to the hospital. In this study, we found a significant association between the level of stigmatization and the individual's willingness to go to the hospital. In addition to the stigma concerning COVID19 , the fear of being infected in the hospital and getting quarantined was another reason for the refusal to go to the hospital. This fear was further exacerbated by the large number of health personnel infected with COVID-19 in Cameroon [15].

\section{Conclusion}

The hospital turnout in Buea municipality experienced a drop in the lone COVID-19 treatment centre and an increase in other health facilities between April and June 2020. Individuals with COVID-19 like symptoms were stigmatized and this probably accounted for their refusal to seek treatment in the regional hospital (COVID-19 treatment center) and their willingness to resort to auto-medication if infected.

\section{Funding Source}

The authors did not receive support from any organization for the submitted work.

\section{Competing Interest}

The authors have no conflicts of interest to declare that are relevant to the content of this article.

\section{Acknowledgements}

We wish to acknowledge all the community members who took part in this study and the hospitals facilities that provided data for the study.

\section{References}

[1] Singhal, T. (2020). A Review of Coronavirus Disease-2019 (COVID-19). The Indian Journal of Pediatrics, 87 (4), 281286. https://doi.org/10.1007/s12098-020-03263-6.

[2] Zhu, N., Zhang, D., Wang, W., Li, X., Yang, B., Song, J., Zhao, X., Huang, B., Shi, W., Lu, R., Niu, P., Zhan, F., Ma, X., Wang, D., Xu, W., Wu, G., Gao, G. F., Tan, W., \& China Novel Coronavirus Investigating and Research Team. (2020). A Novel Coronavirus from Patients with Pneumonia in China, 2019. The New England Journal of Medicine, 382 (8), 727 733. https://doi.org/10.1056/NEJMoa2001017.

[3] WHO Director-General's opening remarks at the media briefing on COVID-19-11 March 2020. (n.d.). Retrieved 31 May 2020, from https://www.who.int/dg/speeches/detail/whodirector-general-s-opening-remarks-at-the-media-briefing-oncovid-19---11-march-2020. 
[4] Ramaci, T., Barattucci, M., Ledda, C., \& Rapisarda, V. (2020). Social Stigma during COVID-19 and its Impact on HCWs $\begin{array}{lllll}\text { Outcomes. } & \text { Sustainability, } & 12 & \text { (9), } & 3834 .\end{array}$ https://doi.org/10.3390/su12093834.

[5] Adom, D., \& Adu Mensah, J. (2020b). The Psychological Distress and Mental Health Disorders from COVID-19 Stigmatization in Ghana. SSRN Electronic Journal. https://doi.org/10.2139/ssrn.3599756.

[6] Ren, S.-Y., Gao, R.-D., \& Chen, Y.-L. (2020). Fear can be more harmful than the severe acute respiratory syndrome coronavirus 2 in controlling the corona virus disease 2019 epidemic. World Journal of Clinical Cases, 8 (4), 652-657. https://doi.org/10.12998/wjcc.v8.i4.652.

[7] Singh, R., \& Subedi, M. (2020). COVID-19 and stigma: Social discrimination towards frontline healthcare providers and COVID-19 recovered patients in Nepal. Asian Journal of Psychiatry, 53 , 102222 https://doi.org/10.1016/j.ajp.2020.102222.

[8] Barnett, M. L., Hu, L., Martin, T., \& Grabowski, D. C. (2020). Mortality, Admissions, and Patient Census at SNFs in 3 US Cities During the COVID-19 Pandemic. JAMA. https://doi.org/10.1001/jama.2020.11642.

[9] Baum, A., \& Schwartz, M. D. (2020). Admissions to Veterans Affairs Hospitals for Emergency Conditions During the COVID-19 Pandemic. JAMA, 324 (1), 96-99. https://doi.org/10.1001/jama.2020.9972.

[10] Hourston, G. J. M. (2020). The impact of despecialisation and redeployment on surgical training in the midst of the COVID-
19 pandemic. International Journal of Surgery (London, England), 78, 1-2. https://doi.org/10.1016/j.ijsu.2020.03.082.

[11] Tam, C.-C. F., Cheung, K.-S., Lam, S., Wong, A., Yung, A., Sze, M., Fang, J., Tse, H.-F., \& Siu, C.-W. (2020). Impact of coronavirus disease 2019 (COVID-19) outbreak on outcome of myocardial infarction in Hong Kong, China. Catheterization and Cardiovascular Interventions: Official Journal of the Society for Cardiac Angiography \& Interventions. https://doi.org/10.1002/ccd.28943.

[12] Aacharya, R. P., \& Shah, A. (2020). Ethical dimensions of stigma and discrimination in Nepal during COVID-19 pandemic. Ethics, Medicine, and Public Health. https://doi.org/10.1016/j.jemep.2020.100536.

[13] Nicholas, T., Mandaah, F. V., Esemu, S. N., Vanessa, A. B. T., Gilchrist, K. T. D., Vanessa, L. F., \& Shey, N. D. (2020). COVID-19 knowledge, attitudes and practices in a conflict affected area of the South West Region of Cameroon. The Pan African Medical Journal, 35 (34), Article 34. https://doi.org/10.11604/pamj.supp.2020.35.2.22963.

[14] See, L.-C., Shen, Y.-M., Chen, C.-L., Huang, T.-M., Huang, Y.-H., Huang, H.-C., \& Lin, S.-R. (2011). Professional attitude of health care workers toward serving HIV/AIDS patients and drug users: Questionnaire design and evaluation of reliability and validity. AIDS Care, 23 (11), 1448-1455. https://doi.org/10.1080/09540121.2011.565023.

[15] Cameroon Situation Report (2020). Centre des operations d'urgence de sante publique; No 42, Periode du 29/07/2020 au $05 / 08 / 2020$ 